\title{
Serum amyloid A concentration in foals - Can it help when making a treatment decision in foals with pneumonia?
}

\author{
Rebecca Thomé ${ }^{7}$, Corinna Weber ${ }^{2}$, Karl Rohn ${ }^{3}$ and Monica Venner ${ }^{4}$ \\ 1 University of Veterinary Medicine Hannover, Clinic for Horses, Hanover, Germany \\ 2 LABOKLIN GmbH\&Co.KG, Bad Kissingen, Germany \\ 3 University of Veterinary Medicine Hanover, Department of Biometry and Epidemiology, Hannover, Germany \\ ${ }^{4}$ Clinic Destedt, Destedt, Germany
}

\begin{abstract}
Summary: Bronchopneumonia is a frequent and serious pulmonary disorder in foals on equine breeding farms and the most common pathogens responsible for this condition are Streptococcus equi ssp. zooepidemicus (Strep. eq. ssp. zoo.) and Rhodococcus equi (R. equi). As foal pneumonia occurs endemically on many studs worldwide, practitioners are asked to evaluate regularly all foals in order to detect early affected foals and reduce the losses. Some of those will show neither clinical symptoms nor hematological changes but obvious pulmonary lesions at sonography. Consequently the question of treating these foals will rise. The aim of the study was to evaluate the serum amyloid A (SAA) concentration in clinically healthy or mildly sick foals showing either no findings, moderate or severe findings at lung sonography. The investigation was a prospective study. A total of 33 foals were examined once weekly starting at the age of two weeks over a period of four months. Clinical signs, body temperature, ultrasonographical pulmonary findings and haematological findings including WBC count and SAA serum concentrations were monitored. After each sonographical examination of the lung, the diameters of pulmonary consolidations were added to obtain an abscess score that represents the severity of pulmonary disease of these foals. The frozen serum samples of the 33 foals were analysed at different stages of pneumonia. Altogether, 49 samples of healthy state (abscess score $=0 \mathrm{~cm}$ ), 31 of moderately sick state (abscess score $=1-9 \mathrm{~cm}$, no indication for treatment) and 22 of severe pulmonary damage (abscess score $>10 \mathrm{~cm}$, indication for treatment) were analysed by enzyme-linked immunosorbent assay to determine the SAA concentration. The median SAA was $18 \mu \mathrm{g} / \mathrm{ml}$ (25th percentile: $1.5 \mu / \mathrm{ml} ; 75$ th percentile: $52.7 \mu \mathrm{g} / \mathrm{ml})$ in the healthy foals, $5.6 \mu \mathrm{g} / \mathrm{ml}(25 \mathrm{th}: 2.4 \mu \mathrm{g} / \mathrm{ml} ; 75 \mathrm{th}$ : $82.3 \mu \mathrm{g} / \mathrm{ml})$ in the moderately sick foals and $80.2 \mu \mathrm{g} / \mathrm{ml}(25 \mathrm{th}: 79.3 \mu \mathrm{g} / \mathrm{ml} ; 75 \mathrm{th}: 160 \mu \mathrm{g} / \mathrm{ml})$ in the foals requiring treatment. These results show that the SAA concentration might be considered as an efficient parameter for making a treatment decision in foals in the early course of pneumonia.
\end{abstract}

Keywords: Serum amyloid A, concentration, foal, pneumonia, treatment, diagnostic

Citation: Thomé R., Weber C., Rohn K., Venner M. (2018) Serum amyloid A concentration in foals - Can it help when making a treatment decision in foals with pneumonia? Pferdeheilkunde 34, 61-67; DOI 10.21836/PEM20180111

Correspondence: Venner PD Dr. PhD, Equine Clinic, Trift 4, 38162 Destedt, Germany; mvenner@gmx.de

\section{Introduction}

Bronchopneumonia is a frequent and serious pulmonary disorder in foals on equine breeding farms. The most common pathogens responsible for this condition are Streptococcus equi ssp. zooepidemicus (Strep. eq. ssp. zoo.) and Rhodococcus equi (R. equi). The bacterium has been thoroughly investigated lately due to the endemic progression of pneumonia caused by R. equi on many breeding farms. Foals, in particular those between one and six months of age often suffer from severe pyogranulomatous bronchopneumonia caused by R. equi (Magnusson 1923, Zink et al. 1986, Giguère and Prescott 1997). Earlier investigations have shown that pneumonia in foals occurs mainly subclinically in early stages of the disease and this makes early detection very difficult (Althaus 2004, Slovis et al. 2005, Venner et al. 2012). Many foals show neither clinical signs nor haematological abnormalities until the pulmonary damage is severe. Consequently, different diagnostic methods for early detection of pneumonia in foals, such as clinical signs, haematology (white blood cells, acute phase proteins: APPs) and diagnostic imaging tools (radiology, ultrasonography), have been evaluated in the past (Giguère et al. 2003, Leclère et al. 2011 , Chaffin et al. 2013, Giguère et al. 2016).
The ultrasonographic examination of the lung was shown to be the most sensitive diagnostic method in the early course of pneumonia in foals (Weimar 2006). However, not only the early detection of pneumonia in foals is difficult, but also making a treatment decision has been challenging, as earlier studies have shown that foals possess good self-healing capacity in moderate stages of pneumonia (Althaus 2004, Venner 2009, Hildebrand et al. 2015). The abscess score is the major parameter currently used to make the treatment decision. Some authors advise the cut-off of $10 \mathrm{~cm}$, above which foals should be treated straight away (Rutenberg et al. 2017). Acute phase proteins (APPs) have been discussed recently as a promising parameter for monitoring pneumonia in foals (Hultén and Demmers 2002, Cohen et al. 2005, Passamonti et al. 2015, Giguère et al. 2016). These APPs are specific indicators for inflammatory processes. Traumatic injuries, surgery, autoimmune diseases and, finally, viral or bacterial infections are major inflammatory events associated with an elevated APP concentration in horses (Gabay and Kushner 1999). Fibrinogen and the serum amyloid $A$ (SAA) are the APPs most frequently measured in horses. Both proteins are positive major APPs which have a low or even undetectable serum concentration in healthy individuals and have shown an up to 1000-fold increase in response to inflamma- 
tion of any kind (Gabay and Kushner 1999, Hultèn et al. 1999, Belgrave et al. 2013). The SAA, however, shows a more rapid increase and decrease in serum concentration during the inflammatory and healing process in contrast to fibrinogen. Therefore, SAA seems to be more sensitive in the diagnosis of pneumonia in foals than fibrinogen (Hultèn et al. 1999, Hultèn and Demmers 2002).

The aim of the study was to evaluate the serum amyloid $A$ (SAA) concentration in clinically healthy or at the most mildly sick foals showing either no findings, moderate or severe findings at lung sonography. A further objective was to analyze whether there is a correlation between the SAA concentration and severity of pulmonary damage. An additional aim of the study was to evaluate the diagnostic value of SAA for making a treatment decision in foals suffering from pneumonia.

\section{Method}

Thirty-three foals on a German breeding farm with endemic rhodococcosis underwent the screening protocol established since 12 years on the breeding farm in order to detect early foals with pneumonia. Consequently, these foals were examined once weekly starting at the age of two weeks over a period of four months. The examination procedure included a physical examination to determine the clinical score, the inner body temperature, haematology and, finally, an ultrasonographic examination of the thorax as the reference method for the detection of pneumonia (see below).

All foals grew up under the same housing, hygiene and medical management. Each foal was examined once weekly and the findings on temperature, size and texture of the mandibular lymph nodes, nasal discharge classified as either serous, mucus or purulent, and auscultations of the trachea and lung were recorded. The findings were given a score and eventually added to a clinical score (Gravert 2006). The foals were then classified as 'clinically healthy' $(0-2)$, 'moderately sick' $(3-6)$ or 'severely sick' ( $\geq 7)$.

The haematological examination included the determination of the WBC count and measurement of the SAA serum concentration in foals once weekly. The blood samples were taken via jugular venipuncture and immediately filled into EDTA and plain tubes for further processing. The EDTA tubes were analysed using an automated cell counter, SYSMEX KX $21 \mathrm{~N}$, on the same day for the measurement of the WBC count. After the blood in the plain tubes clotted, it was centrifuged for about $10 \mathrm{~min}$, and the supernatant designated as serum was filled into small aliquots $(2 \mathrm{ml})$, which were then stored at $-20^{\circ} \mathrm{C}$. Further evaluation of the SAA was performed upon completion of the study by an external laboratory (LABOKLIN

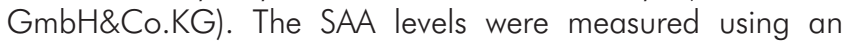
enzyme-linked immunosorbent assay (ELISA), according to the manufacturer's protocol. The measuring range was between 2.5 and $40 \mu \mathrm{g} / \mathrm{ml}$ with an intra-assay coefficient of variation of $4.6 \%$ and an inter-assay coefficient of variation of $8.5 \%$. Samples with an SAA concentration above $40 \mu \mathrm{g} / \mathrm{ml}$ were diluted and reanalysed to calculate the exact SAA concentration.

A portable ultrasound machine SONOVET 2000 (Osteosys Co, Seoul, Korea) with a $7.5 \mathrm{MHz}$ linear transducer (LV5-
9AD, SonoAce, Osteosys Co, Seoul, Korea) was used to detect and monitor pulmonary abscesses in foals. Isopropyl alcohol (2-Propanol, 99.5\%, Rebo-Pharm, Bochholt, Germany) was sprayed on both sides of the thorax to achieve sufficient coupling. The ultrasonographical examination was performed from the 15th to the 3th intercostal space, dorsally to ventrally, to detect pulmonary abnormalities adjacent to the pleura (Thomé et al. submitted). Consolidated areas with a diameter above $1 \mathrm{~cm}$ were classified as an abscess and documented in a score sheet. Exemplarily, when a consolidation was found at sonography, the diameter was measured and written into the corresponding lung sheet. At the end of the examination, all diameters of diagnosed consolidations were added, resulting in the so-called abscess score, which represents the severity of pulmonary damage.

The severity of lung lesions was arranged into three categories: abscess score of $0 \mathrm{~cm}$, abscess score from 1 to $9 \mathrm{~cm}$ and abscess score $\geq 10 \mathrm{~cm}$. An abscess score $\geq 10 \mathrm{~cm}$ of diameter represents high pulmonary damage, which is the cut-off value for making an antimicrobial treatment decision (Rutenberg et al. 2017).

The Statistical Analysis System for Windows SAS ${ }^{\circledR}$, version 9.4 (SAS ${ }^{\circledR}$ Enterprise Guide version 7.1 Client, SAS Institute Inc. Cary, USA) was used to analyse the data collected. Error probabilities of $p<0.05$, were considered significant for the complete analysis performed. The age of the foals, the SAA concentration, WBC count, clinical score, temperature and abscess score were tested for normal distribution by the Shapiro Wilk's test on the day of initiating antimicrobial therapy in foals with pneumonia. As the data were not normally distributed, the median with the percentiles $(25 \% ; 75 \%)$ was determined.

Temperature, WBC count and SAA concentrations, the Kruskal-Wallis test, and a non-parametric ANOVA on ranks was performed with post hoc Dunn's test for multiple pair wise comparisons to test the global null hypothesis of all three pulmonary damage categories in correlation with the median clinical score.

After calculating a logistic regression model, the receiving operating characteristic (ROC) was used to determine the diagnostic performance of the SAA concentration in foals with severe pulmonary damage (abscess score $\geq 10 \mathrm{~cm}$ ) in order to make a treatment decision. The area under the curve (AUC) is a quality feature of the overall diagnostic performance and relates to the ROC curve. The AUC is classified as follows: non-informative (0.5), less accurate $(0.5-0.7)$, moderately accurate (0.7-0.9) and highly accurate (0.9-1.0) (Greiner et al. 2000). The best AUC value for a test is 1 , which means the sensitivity and specificity is at 100\%. The sum of sensitivity and specificity is a maximum for the Youden Index. It describes the best SAA cut-off value, which is derived from the ROC curve.

\section{Results}

Analysis of the clinical score, body temperature, WBC count and SAA concentration was based on the data of 33 foals. Three serum samples each of 30 foals and four serum samples each of three foals were analysed for measurement of the SAA concentration $(n=102)$. The serum samples taken 
represented different health conditions: healthy foals (abscess score $=0 \mathrm{~cm}, \mathrm{n}=49$ ), moderately sick foals (abscess sco$\mathrm{re}=1-9 \mathrm{~cm}, \mathrm{n}=31$ ) and severely sick foals (abscess score $\geq 10 \mathrm{~cm}, \mathrm{n}=22$ ).

The clinical score (median; 25th-75th percentile) of healthy foals was $2(1-2)$ with a minimum of 0 and a maximum of 3 . The body temperature ranged from 37.8 to $39.0^{\circ} \mathrm{C}$ (median: $38.5^{\circ} \mathrm{C}$; 25 th -75 th: $38.2-38.7^{\circ} \mathrm{C}$ ). Additionally, the WBC count in foals with an abscess score of $0 \mathrm{~cm}$ diameter, ranged from 4,100 to 19,400 cells/ L (median: 12,300 cells/ L; 25th-75th: 9,100-14,500 cells/ L). The SAA concentration of healthy foals ranged from $0.1 \mu \mathrm{g} / \mathrm{ml}$ to $161 \mu \mathrm{g} / \mathrm{ml}$ (median: $18 \mu \mathrm{g} / \mathrm{ml} ; 25 \mathrm{th}-75 \mathrm{th}$ : $1.5-52.7 \mu \mathrm{g} / \mathrm{ml}$ ).

Moderately sick foals had a clinical score between 0 and 5 (median: $2 ; 25$ th -75 th: $2-2$ ). The temperature ranged from 37.8 to $40.3^{\circ} \mathrm{C}$ (median: $38.5^{\circ} \mathrm{C}$; 25th-75th: $38.2-38.8^{\circ} \mathrm{C}$ ). The WBC concentration ranged from 7, 100 to 19,600 cells/ L (median: 12,400 cells/ L; 25th-75th: $10,800-14,650$ cells/ L). Moderately sick foals had a SAA concentration range from $0.2 \mu \mathrm{g} / \mathrm{ml}$ to $92.2 \mu \mathrm{g} / \mathrm{ml}$ (median: $5.6 \mu \mathrm{g} / \mathrm{ml} ; 25 \mathrm{th}-75 \mathrm{th}: 2.45-82.35 \mu \mathrm{g} / \mathrm{ml}$ ).

The age at which the foals needed antimicrobial therapy dueto severe pulmonary damage (abscess score $\geq 10 \mathrm{~cm}$ ) varied between 5 and 16 weeks (median: 10 weeks; 25th-75th: 8-13 weeks). In these foals, clinical respiratory findings summarized in the clinical score ranged from 0 to 7 (median: 2; 25th-75th: $2-4)$. The body temperature in association with severe pulmonary damage ranged from 38.1 to $40.9^{\circ} \mathrm{C}$ (median: $38.9^{\circ} \mathrm{C}$; 25 th -75 th: $38.5-39.6^{\circ} \mathrm{C}$ ). The WBC count had its median at 14,550 cells/ L (25th-75th: $12,700-15,425$ cells/ L). The SAA concentration in foals with severe pulmonary damage ranged from $0.6 \mu \mathrm{g} / \mathrm{ml}$ to $167 \mu \mathrm{g} / \mathrm{ml}$ (median: 80.2 $\mathrm{g} / \mathrm{ml}$; 25th-75th: 79.3-160 $\mu \mathrm{g} / \mathrm{ml}$ ).

The clinical score was significantly lower in healthy foals compared to moderately sick foals and to severely sick foals. The clinical score between moderately and severely sick foals did not differ significantly (Tab. 1). The body temperature, WBC count and SAA concentration between healthy and moderately sick foals did not differ significantly (Tab. 1). The body temperature, WBC count and SAA concentration were significantly lower in healthy foals compared to severely sick foals. Additionally, body temperature, WBC count and SAA concentration were significantly lower in moderately sick foals compared to severely sick foals (Fig. 1-4).

The ROC curve (Fig. 5) shows the sensitivity and specificity of different SAA concentration cut-off values in foals suffering of severe pulmonary damage (abscess score $\geq 10 \mathrm{~cm}$ ) (Tab. 2). The AUC, as a quality parameter for the overall diagnostic

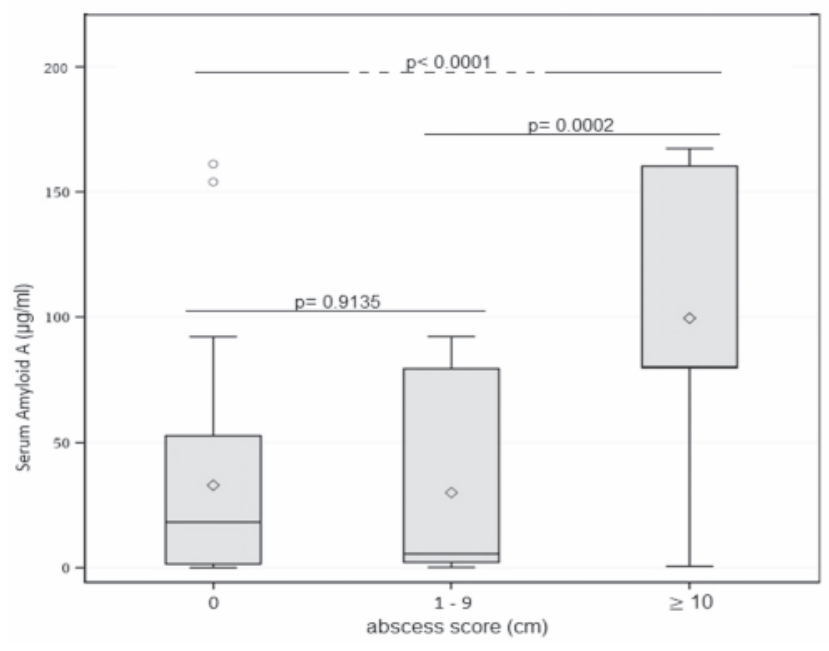

Fig. 1 Distribution of SAA concentrations in healthy foals (abscess score $=0 \mathrm{~cm}, \mathrm{n}=49$ ), moderately sick foals (abscess sco$\mathrm{re}=1-9 \mathrm{~cm}, \mathrm{n}=31$ ) and foals with severe pulmonary damage (abscess score $\geq 10 \mathrm{~cm}, \mathrm{n}=22$ ), diagrammed as tukey Boxplots. Verteilung der SAA Konzentration bei gesunden (Abszess Score $=0 \mathrm{~cm} ; n=49$ ), moderat erkrankten (Abszess Score: $1-9 \mathrm{~cm}$; $n=31$ ) und schwer erkrankten Fohlen (Abszess Score: $\geq 10 \mathrm{~cm}$; $n=22)$, dargestellt als Tukey Boxplots.

Tab. 1 Significance (p) of the clinical score, body temperature, WBC count and SAA concentration between different health conditions (abscess score $=0 \mathrm{~cm}, 1-9 \mathrm{~cm}, 10 \mathrm{~cm}$ ) when $\mathrm{p}<0.5$. | Die Signifikanz (p) des klinischen Scores, der Körpertemperatur, den Blutleukozyten und der SAA Konzentration zwischen unterschiedlichen Gesundheitszuständen (Abszess Score: $0 \mathrm{~cm}, 1-9 \mathrm{~cm}, \geq 10 \mathrm{~cm}$ ) bei $p<0,5$.

\begin{tabular}{ccccc}
\hline abscess score $(\mathrm{cm})$ & $\mathrm{p}$ (clinical score) & $\mathrm{p}$ (temperature) & $\mathrm{p}$ (WBC count) & $\mathrm{p}(\mathrm{SAA})$ \\
\hline $0 / 1-9$ & 0.0019 & 0.5449 & 0.5971 & 0.9135 \\
$0 / 10$ & 0.0088 & 0.0006 & 0.0433 & $<0.0001$ \\
$1-9 / 10$ & 0.8455 & 0.0156 & 0.0490 & 0.0002 \\
\hline
\end{tabular}

Tab. 2 Sensitivity, specificity and probability for the individual SAA concentration cut-off value, on the day of making a decision for therapy. I Die Sensitivitäten, Spezifitäten und Wahrscheinlichkeiten für individuelle SAA Grenzwerte am Tag der Therapieentscheidung.

\begin{tabular}{|c|c|c|c|}
\hline $\begin{array}{c}\text { SAA concentration } \\
(\mu \mathrm{g} / \mathrm{mL})\end{array}$ & $\begin{array}{l}\text { Sensitivity } \\
(\%)\end{array}$ & $\begin{array}{c}\text { Specificity } \\
(\%)\end{array}$ & $\begin{array}{c}\text { Probability } \\
\text { (\%) }\end{array}$ \\
\hline 0.7 & 95.5 & 12.5 & 5.02 \\
\hline 5 & 90.9 & 40.0 & 5.60 \\
\hline 10 & 90.9 & 48.8 & 6.42 \\
\hline 40 & 86.4 & 70.0 & 13.1 \\
\hline 80 & 77.3 & 80.0 & 30.7 \\
\hline 108 & 40.9 & 95.5 & 49.2 \\
\hline 161 & 22.7 & 98.8 & 80.1 \\
\hline
\end{tabular}




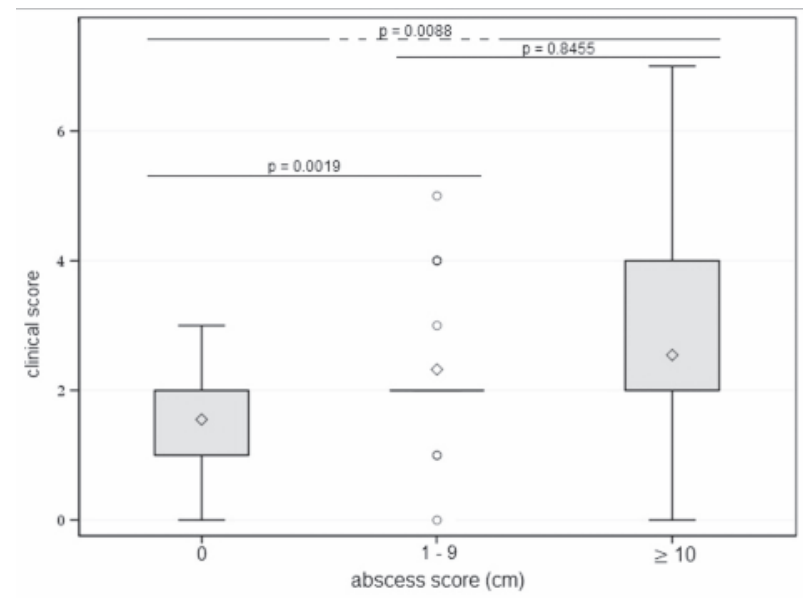

Fig. 2 Distribution of the clinical score in healthy foals $(n=49)$, moderately sick foals $(n=31)$ and foals with severe pulmonary damage $(n=22)$, diagrammed as tukey Boxplots. | Verteilung des klinischen Scores bei gesunden $(n=49)$, moderat erkrankten $(n=37)$ und schwer erkrankten Fohlen $(n=22)$, dargestellt als Tukey Boxplots.

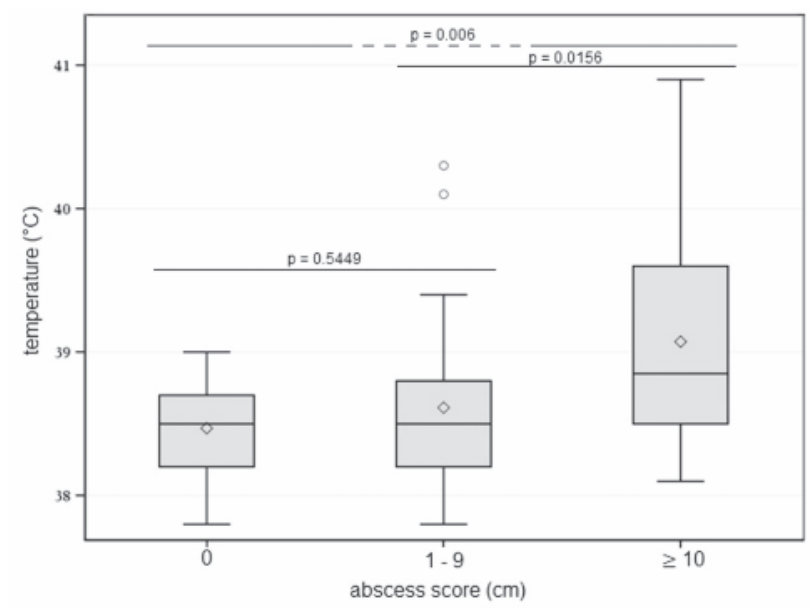

Fig. 3 Distribution of the temperature in healthy foals $(n=49)$, moderately sick foals $(n=31)$ and foals with severe pulmonary damage $(n=22)$, diagrammed as tukey Boxplots. Verteilung der Körpertemperatur von gesunden $(n=49)$, moderat erkrankten $(n=31)$ und schwer erkrankten Fohlen ( $n=22)$, dargestellt als Tukey Boxplots.

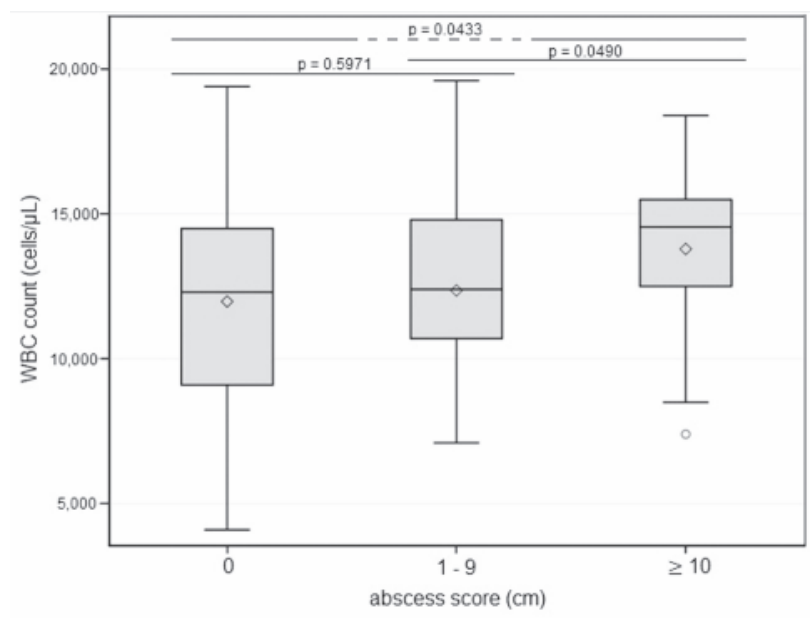

Fig. 4 Distribution of the WBC count in healthy foals $(n=49)$, moderately sick foals $(n=31)$ and foals with severe pulmonary damage $(n=22)$, diagrammed as tukey Boxplots. I Verteilung der Blutleukozyten von gesunden ( $n=49)$, moderat erkrankten $(n=31)$ und schwer erkrankten Fohlen ( $n=22)$, dargestellt als Tukey Boxplots.

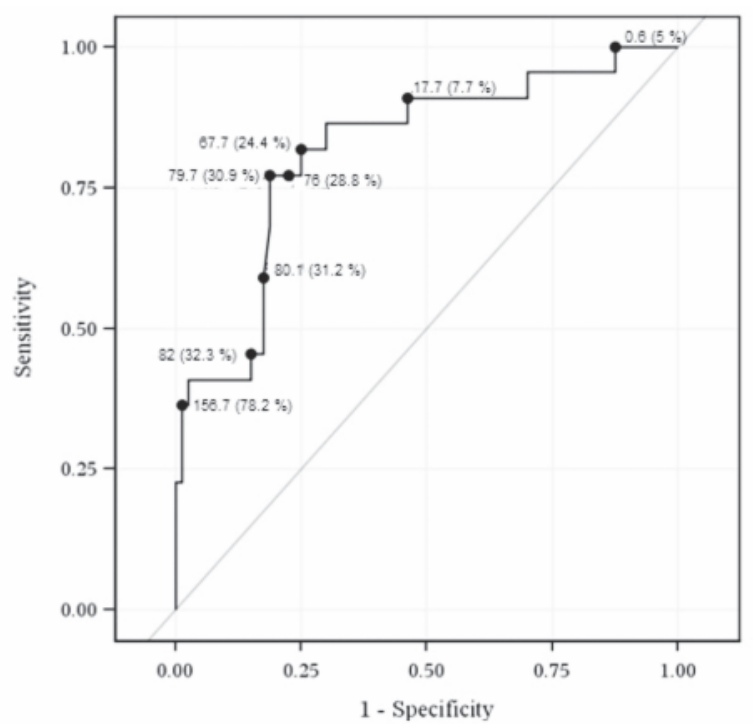

Fig. 5 Sensitivity, specificity and probability of SAA concentrations in foals with severe pulmonary damage (abscess score $\geq 10 \mathrm{~cm}$; $\mathrm{n}=22$ ). I Sensitivität, Spezifität und Wahrscheinlichkeiten der SAA Konzentration bei Fohlen mit schweren pulmonalen Schäden (Abszess Score $\geq 10 \mathrm{~cm} ; n=22$ ).

performance of the SAA protein in order to detect foals which are in need of antimicrobial treatment due to severe pneumonia, was $0.815 \pm 0.054 \quad(95 \%$ confidence interval $(\mathrm{CI})=0.7088-0.9219)$ and significantly different from an area under the curve of 0.5. The Youden Index, described as the optimal SAA concentration cut-off value in foals suffering of severe pneumonia, is at $79.7 \mu \mathrm{g} / \mathrm{ml}$ with a sensitivity of $77.3 \%$ and a specificity of $80.0 \%$ (Tab. 2). Five out of twenty-two foals with severe pulmonary damage showed SAA values below $79.7 \mu \mathrm{g} / \mathrm{ml}$. Additionally, 9 out of 49 healthy foals and 9 out of 31 moderately sick foals showed SAA values above $79.7 \mu \mathrm{g} / \mathrm{ml}$.

\section{Discussion}

Clinical signs, body temperature, WBC count and SAA concentrations of healthy foals (abscess score $=0 \mathrm{~cm}$ ), moderately sick foals (abscess score $=1-9 \mathrm{~cm}$ ) and foals with severe pulmonary damage (abscess score $\geq 10 \mathrm{~cm}$ ) were evaluated in the present study. The SAA concentration was assessed as a possible parameter for making a treatment decision particularly in severely sick foals not yet showing obvious clinical signs of pulmonary damage.

Treatment decision in foals with pneumonia should be made considering their good self-healing capacities (Venner 2009, Hildebrand et al. 2015). A study comparing different treatment protocols for pneumonia in foals at an abscess score $\geq 8 \mathrm{~cm}$ showed that 32 out of 41 foals of a control group had a complete recovery without antimicrobial treatment (Hildebrand et al. 2015). However, another study in which treatment was initiated in foals with an abscess score $\geq 10 \mathrm{~cm}$ showed that only 22 out of 80 foals with pneumonia recovered without needing antimicrobial treatment (Rutenberg et al. 2017). Consequently, an abscess score $\geq 10 \mathrm{~cm}$ was used as the cut-off for the decision of antimicrobial treatment in the present study. 
The best diagnosis of pneumonia in foals can be made by means of diagnostic imaging. Radiology and sonography have been the methods most frequently used and have been validated to give a proper assessment of the severity of pulmonary disorders (Falcon et al. 1985, Althaus 2004). Previous studies which compared the value of both diagnostic methods have shown a higher sensitivity of the ultrasonographical examination for detecting pulmonary consolidations (Ramirez et al. 2004, Venner et al. 2014). Although sonography cannot detect abscesses in the deeper lung tissue (Reef 2004), it can identify more pulmonary consolidations than radiology (Ramirez et al. 2004, Venner et al. 2014). Therefore, the ultrasonographic examination was used in the present study to detect and monitor pulmonary consolidations in foals with pneumonia.

Even though the isolation of the pathogen has been described as a 'gold standard' for the diagnosis pneumonia caused by R. equi (Giguère and Prescott 1997, Giguère et al. 2003), earlier studies have shown that neither PCR nor bacterial culture of airway samples have yielded promising results (Weimar 2006, Venner et al. 2007). Consequently, the diagnosis pneumonia was based on ultrasonographical examination in the present study rather than on isolation of the pathogen.

Clinical signs and haematological findings are well-discussed diagnostic parameters in pneumonia caused by $R$. equi in foals (Zink et al. 1986, Giguère and Prescott 1997, Giguère et al. 2003, Thomé et al. 2017). Foals with severe pulmonary damage showed a significantly higher clinical score, body temperature and WBC count compared to healthy foals in the present study (Tab. 1). Additionally, severely sick foals showed a significantly higher body temperature and WBC count compared to moderately sick foals (Tab. 1). However, the median values of the clinical score $(2)$ and the temperature $\left(38.9^{\circ} \mathrm{C}\right)$ of most severely sick foals were in the physiological range. Only the WBC count had a slightly elevated median value of 14,550 cells/ L. These results are similar to previous studies which evaluated clinical and haematological parameters for early detection of pneumonia in foals (Giguère and Prescott 1997, Giguère et al. 2003, Althaus 2004, Venner 2009, Thomé et al. submitted). Consequently, clinical signs and haematological findings are not reliable parameters in early stages of pneumonia. However, these parameters can support the diagnosis of pneumonia in advanced stages of pulmonary damage in foals.

The focus of the present investigation was the evaluation of the SAA concentration in healthy, moderately sick and severely sick foals. Therefore, the diagnostic performance of SAA concentrations in helping to make a treatment decision in foals with pneumonia was assessed. Surprisingly, the SAA concentration in foals with severe pulmonary damage was significantly higher compared to healthy or moderately sick foals (Fig. 1). However, no significant difference in SAA concentration was shown between healthy and moderately sick foals (Fig. 1). Our results show that moderately sick foals had a low median SAA concentration of $5.6 \mu \mathrm{g} / \mathrm{ml}$. This might be explained by that fact that most foals first develop a subclinical pneumonia, in which neither clinical nor haematological abnormalities are to be expected (Giguère and Prescott 1997, Thomé et al. submitted). Therefore, diagnostic imaging is necessary to detect and monitor pneumonia in mode- rately sick foals (Althaus 2004, Gravert 2006, Thomé et al. submitted). Consequently, the SAA concentration does not seems to be a reliable parameter for detecting foals with moderate pulmonary damage.

Nevertheless, the results show a significant correlation between severe pulmonary damage and elevated SAA concentrations in pneumonic foals (Fig. 1). This is the first report on data showing a good diagnostic value of SAA in foals with severe pneumonia. Moreover, the SAA concentration seems to be a proper parameter to use in the process of making a decision to treat a foal with pneumonia. In the present investigation for making a treatment decision in foals with pneumonia, the optimum SAA cut-off value is at $79.7 \mu \mathrm{g} / \mathrm{ml}$ with a sensitivity of $77.3 \%$ and a specificity of $80.0 \%$ (Tab. 2). Only 5 out of 22 foals had an SAA concentration below $79.7 \mu \mathrm{g} / \mathrm{ml}$ when showing an abscess score above $10 \mathrm{~cm}$ diameter. Therefore, the optimum SAA cut-off value with an AUC of $0.815 \pm 0.054$ indicates a moderate diagnostic value for making a treatment decision in foals with severe pulmonary damage.

However, SAA concentrations above $79.7 \mu \mathrm{g} / \mathrm{ml}$ also appeared in a small group of healthy (9/49) and moderately sick (9/31) foals, which did not need antimicrobial treatment. Because sonographic examination was used as a diagnostic tool for diagnosing pneumonia in the present investigation, pulmonary consolidations in the deep lung tissue might have been present, but not detected in these 18 foals (Ramirez et al. 2004). Further diagnostics, such as radiographical examination, is recommended to clarify the deviating results. However, further diagnostics was not possible, as the SAA analysis was performed on archived serum samples which were analysed after completion of the study. Previous studies also reported elevated SAA concentrations in foals without signs of pneumonia (Cohen et al. 2005, Giguère et al. 2016). In these investigations, the SAA analysis was also performed on archived serum samples, whereas further diagnostics of the patients had not been performed (Cohen et al. 2005, Giguère et al. 2016). Therefore, an immediate SAA analysis is recommended to make the decision for further diagnostic investigations on a foal with no clinical findings, normal haematology and normal ultrasonography of the thorax. In case the SAA value is increased, further investigations, such as chest radiographs or ultrasonographic examination of the abdomen, might be considered to assess further inflammatory processes.

Nevertheless, 5 out of 22 foals with severe pulmonary damage showed SAA concentrations below the optimum SAA cutoff value of $79.7 \mu \mathrm{g} / \mathrm{ml}$. The reason why some foals show low SAA concentrations despite high-grade lung lesions is still not completely explained. However, as the SAA serum concentration increases very rapidly over six to twelve hours, with a halflife of 30 to 120 minutes (Tape and Kisilevsky 1989), shorter sampling intervals might be more conclusive.

\section{Conclusion}

Our results show that clinical and haematological parameters are not reliable parameters in early stages of pneumonia and also have only low relevance in foals with severe pulmonary damage. Furthermore, the SAA concentration has shown to be a sensitive parameter to make a treatment decision in 
foals suffering from severe pneumonia. Nevertheless, making a treatment decision in foals based only on the SAA concentration cannot be recommended. The use of SAA is much more of a good additional tool to ultrasonography to detect and monitor severe pneumonia in foals. It is the authors belief that examining foals by means of sonography still provides the highest sensitivity for making a treatment decision in foals with pneumonia.

\section{References}

Althaus O. P. (2004) Sonographie: Eine Hilfe zur Früherkennung von Rhodococcus equi-Pneumonie beim Fohlen. Diss. Med. Vet. Hannover

Belgrave R. L., Dickey M. M., Arheart K. L., Cray C. (2013). Assessment of serum amyloid $A$ testing of horses and its clinical application in a specialized equine practice. J. Am. Vet. Med. Assoc. 243, 113-119

Chaffin M. K., Cohen N. D., Blodgett G. P., Syndergaard M. (2013) Evaluation of hematologic screening methods for predicting subsequent onset of clinically apparent Rhodococcus equi pneumonia in foals. Am. Assoc. Equine Pract. 59, 267

Cohen N. D., Chaffin M. K., Vandenplas M. L., Edwards R. F., Nevill M., Moore J. N, Martens R. J. (2005) Study of serum amyloid A concentrations as a means of achieving early diagnosis of Rhodococcus equi pneumonia. Equine Vet. J. 37, 212-216

Falcon J., Smith B. P., O'Brien T. R., Carlson G. P., Biberstein E. (1985) Clinical and radiographic findings in Corynebacterium equi pneumonia of foals. J. Am. Vet. Med. Ass. 186, 593-599

Gabay C., Kushner I. (1999) Acute - Phase proteins and other systemic responses to inflammation. N. Engl. J. Med. 340, 448-454

Giguère S., Berghaus L. J., Miller C. D. (2016) Clinical Assessment of a Point-of-Care Serum Amyloid A Assay in Foals with Bronchopneumonia. J. Vet. Intern. Med. 30, 1338-1343

Giguère S., Hernandez J., Gaskin J., Miller C., Bowman J. L. (2003) Evaluation of white blood cell concentration, plasma fibrinogen concentration and an agar gel immunodiffusion test for early identification of foals with Rhodococcus equi pneumonia. J. Am. Vet. Med. Assoc. 222, 775-781

Giguère S., Prescott J. F. (1997) Clinical manifestations, diagnosis, treatment and prevention of Rhodococcus equi infections in foals. Vet. Microbiol. 56, 313-334

Gravert I. (2006) Zur Entwicklung von früh erkannten Lungenabszessen beim Fohlen ohne Behandlung. Diss. Med. Vet. Hannover

Greiner M., Pfeiffer D., Smith R. D. (2000) Principles and practical application of the receiver-operating characteristic analysis for diagnostic tests. Prev. Vet. Med. 45, 23-41

Hildebrand F., Venner M., Giguère S. (2015) Efficacy of gamithromycin for the treatment of foals with mild to moderate bronchopneumonia. J. Vet. Intern. Med. 29, 333-338

Hultén C., Demmers S. (2002) Serum amyloid A (SAA) as an aid in the management of infectious disease in the foal: comparison with total leucocyte count, neutrophil count and fibrinogen. Equine Vet. J. $34,693-698$
Hultén C., Tulamo R.-M., Suominen M. M., Burvall K., Marhaug G., Forsberg M. (1999) A non-competitive chemiluminescence enzyme immunoassay for the equine acute phase protein serum amyloid A (SAA) - a clinically useful inflammatory marker in the horse. Vet. Immunol. Immunopathol. 68, 267-281

Leclère M., Magdesian K. G., Kass P. H., Pusterla N., Rhodes D. M. (2011) Comparison of the clinical, microbiological, radiological and haematological features of foals with pneumonia caused by Rhodococcus equi and other bacteria. Vet. J. 187, 109-112

Magnusson H. (1923) Spezifische infektiöse Pneumonie beim fohlen: Ein never Eitererreger beim Pferd. Arch. Wiss. Prakt. Tierheilkd. 50, 22-38

Passamonti F., Vardi D. M., Stefanetti V., Marenzoni M. L., Prato S., Cévese P., Coletti M., Pepe M., Casagrande Proietti P., OleaPopelka F. (2015) Rhodococcus equi pneumonia in foals: An assessment of the early diagnostic value of serum amyloid $A$ and plasma fibrinogen concentrations in equine clinical practice. Vet. J. 203, 211-218

Ramirez S., Lester G. D., Roberts G. R. (2004) Diagnostic contribution of the thoracic ultrasonography in 17 foals with Rhodococcus equi pneumonia. Vet. Radiol. Ultrasound 45, 2-5

Reef V. B., Whittier M., Griswold Allam L. (2004) Thoracic ultrasonography. Clin. Tech. Equine Pract. 3, 284-293

Rutenberg D., Venner M., Giguère S. (2017) Efficacy of tulathromycin for the treatment of foals with mild to moderate bronchopneumonia. J. Vet. Intern. Med. 1-6

Slovis N. M., McCracken J. L., Mundy G. (2005) How to use thoracic ultrasound to screen foals for Rhodococcus equi at affected farms. Proc. Am. Assoc. Equine Pract. 51, 274-278

Tape C., Kisilevsky R. (1989) Apolipoprotein A-I and apolipoprotein SAA half-lives during acute inflammation and amyloidogenesis. Biochim. Biophys. Acta 1043, 295-300

Thomé R., Rohn K., Venner M. (submitted 2017) Clinical and haematological parameters for the early diagnosis of pneumonia in foals. Pferdeheilkunde.

Venner M. (2009) Untersuchungen zur Rhodococcus equi-Pneumonie des Fohlens: Diagnostik, Therapie, Prävention. Habil. Vet. Med. Hannover

Venner M., Heyers P., Strutzberg-Minder K., Lorenz N., Verspohl J., Klug E. (2007) Detection of Rhodococcus equi by microbiological culture and by polymerase chain reaction in samples of tracheobronchial secretions of foals. Berl. Münch. Tierärztl. Wschr. $120,126-133$

Venner M., Rödiger A., Lämmer M., Giguère S. (2012) Failure of antimicrobial therapy to accelerate spontaneous healing of subclinical pulmonary abscesses on a farm with endemic infections caused by Rhodococcus equi. Vet. J. 192, 293-298

Venner M., Walther S. M., Münzer B., Stadler P. (2014) Diagnostic of pulmonary abscesses in foals - Comparison of sonographic and radiographic examination. Pferdeheilkunde 30, 561-566

Weimar B. M. (2006) Lungenabszesse bei Fohlen: Klinische, sonographische, endoskopischen, pathomorphologische und mikrobiologische Befunde. Diss. Med. Vet. Hannover

Zink M. C., Yager J. A., Smart N. L. (1986) Corynebacterium equi infections in horses, 1958-1984: a review of 131 cases. Can. J. Vet. Res. 27, 213-217 